\title{
Neuromodulation for Pain: A Comprehensive Survey and Systematic Review of Clinical Trials and Connectomic Analysis of Brain Targets
}

\author{
Kazuaki Yamamoto ${ }^{a}$ Gavin J.B. Elias ${ }^{a}$ Michelle E. Beyn ${ }^{a} \quad$ Ajmal Zemmar $^{a}$ b \\ Aaron Loh $^{a}$ Can Sarica ${ }^{a}$ Jürgen Germann ${ }^{a}$ Roohie Parmar ${ }^{a}$ Emily H.Y. Wong ${ }^{a}$ \\ Alexandre Boutet $^{\mathrm{a}, \mathrm{c}}$ Suneil Kalia ${ }^{\mathrm{a}}$ Mojgan Hodaie ${ }^{\mathrm{a}}$ Andres M. Lozano $^{\mathrm{a}}$ \\ aDivision of Neurosurgery, Department of Surgery, University Health Network and University of Toronto, Toronto, ON, \\ Canada; 'bepartment of Neurosurgery, People's Hospital of Zhengzhou University, Henan Provincial People's Hospital, \\ Henan University People's Hospital, Henan University School of Medicine, Zhengzhou, China; 'Joint Department of \\ Medical Imaging, University of Toronto, Toronto, ON, Canada
}

\section{Keywords \\ Chronic pain · Clinical trials · Connectomic mapping analysis · Neuromodulation · Pain pathways}

\begin{abstract}
Background: Chronic pain is a debilitating condition that imposes a tremendous burden on health-care systems around the world. While frontline treatments for chronic pain involve pharmacological and psychological approaches, neuromodulation can be considered for treatment-resistant cases. Neuromodulatory approaches for pain are diverse in both modality and target and their mechanism of action is incompletely understood. Objectives: The objectives of this study were to (i) understand the current landscape of pain neuromodulation research through a comprehensive survey of past and current registered clinical trials (ii) investigate the network underpinnings of these neuromodulatory treatments by performing a connectomic mapping analysis of cortical and subcortical brain targets that have been stimulated for pain relief. Methods: A search for clinical trials involving pain neuromodulation was conducted using 2 major trial databases (ClinicalTrials.gov and the International Clinical Trials Registry Platform). Trials were catego-
\end{abstract}

karger@karger.com www.karger.com/sfn

Karger $\stackrel{\text { ' }}{5}$
(C) 2021 The Author(s)

Published by S. Karger AG, Basel

This is an Open Access article licensed under the Creative Commons Attribution-NonCommercial-4.0 International License (CC BY-NC) (http://www.karger.com/Services/OpenAccessLicense), applicable to the online version of the article only. Usage and distribution for commercial purposes requires written permission. rized by variables and analyzed to gain an overview of the contemporary research landscape. Additionally, a connectomic mapping analysis was performed to investigate the network connectivity patterns of analgesic brain stimulation targets using a normative connectome based on a functional magnetic resonance imaging dataset. Results: In total, 487 relevant clinical trials were identified. Noninvasive cortical stimulation and spinal cord stimulation trials represented 49.3 and $43.7 \%$ of this count, respectively, while deep brain stimulation trials accounted for $<3 \%$. The mapping analysis revealed that superficial target connectomics overlapped with deep target connectomics, suggesting a common pain network across the targets. Conclusions: Research for pain neuromodulation is a rapidly growing field. Our connectomic network analysis reinforced existing knowledge of the pain matrix, identifying both well-described hubs and more obscure structures. Further studies are needed to decode the circuits underlying pain relief and determine the most effective targets for neuromodulatory treatment.

(c) 2021 The Author(s)

Published by S. Karger AG, Basel

Kazuaki Yamamoto and Gavin J. B. Elias contributed equally to this work.
Correspondence to:

Andres M. Lozano, lozano@uhnresearch.ca 


\section{Introduction}

Chronic pain - generally defined as sustained or recurrent pain lasting longer than 3 months - is a common but often challenging condition $[1,2]$. Chronic pain is highly prevalent, affecting approximately $20-30 \%$ of adults, and can severely affect patient's quality of life [3-6]. Given that the mean annual cost per patient with chronic pain ranges from USD 5,600 to 8,400, chronic pain thus exerts a large financial burden on health-care systems across the world $[1,7,8]$.

While pharmacological interventions can target the pain of various etiologies [9], these treatments can be associated with considerable morbidity and many patients are refractory to medical treatment alone $[10,11]$. For these reasons, and due to the complex and diverse nature of chronic pain, multidisciplinary approaches including interventional therapies are of growing importance [12]. After the failure of conservative medical management due to lack of efficacy or intolerable adverse effects, neuromodulation may be considered as a treatment option for pain relief [13]. To date, multiple neuromodulation techniques, including invasive and noninvasive brain stimulation as well as spinal cord stimulation (SCS) [13, 14], have been studied. Many of these have shown promising results in the context of both nociceptive and neuropathic pain, although their mechanisms of action remain incompletely understood $[13,15]$. Novel treatments and targets continue to be investigated [16].

In this study, we first surveyed and analyzed clinical trials on neuromodulatory therapies for pain to gain an overview of the contemporary research landscape. Prior studies by our group have employed this approach to reveal novel insights into research involving deep brain stimulation (DBS), SCS, and other neurosurgical interventions [17-19]. These surveys serve as a valuable complement to traditional systemic reviews and meta-analyses, which are important for summarizing scientific evidence but do not necessarily provide insights into ongoing trends in fast-moving research environments given their reliance on already published studies. By contrast, clinical trial surveys facilitate an up-to-date assessment of both past and present research and can point toward potential future developments.

Additionally, we investigated the network connectivity patterns of analgesic brain stimulation targets using a normative connectome based on a large functional magnetic resonance imaging (fMRI) dataset $[20,21]$. Because multiple neuromodulatory modalities and targets can relieve pain of various etiologies, we hypothesized that they might engage a common pain network.

Clinical Trials for Pain Neuromodulation and Brain Networks

\section{Methods and Materials}

\section{Data Collection}

A comprehensive search for past and ongoing clinical trials involving neuromodulation for pain was conducted using 2 publicly available trial registries: the International Clinical Trials Registry Platform ([ICTRP]; https://www.who.int/ictrp/en/) and ClinicalTrials.gov (https://clinicaltrials.gov) in March 2020. Detailed information about this search and the subsequent screening and data extraction steps are provided in the online supplementary material, available at www.karger.com/doi/10.1159/000517873. Briefly, each database was interrogated separately using the search terms specified in online suppl. Tables S1 and S2. Unique trial entries identified by this search process were then screened for relevance to neuromodulation for pain by 2 independent reviewers (KY and $\mathrm{MEB}$ ), with disagreements being settled by a third reviewer (GJBE) in accordance with PRISMA guidelines (see PRISMA checklist in the online suppl. material). Relevant trials were defined as those that investigated clinical outcomes of nonlesional neuromodulation administered for pain indications. As such, trials involving interventions such as acupuncture or ablative therapies were excluded.

\section{Variable Extraction and Connectomic Mapping}

Having been screened, clinical trials were categorized by a number of variables, including date of registration, completion status, neuromodulation modality, and target (see Table 1 for a summary of all variables). Publications related to these trials were identified using a stepwise approach involving (i) inspecting each trial entry for automatically indexed publications (ii) searching the PubMed (https://pubmed.ncbi.nlm.nih.gov) and Google Scholar (https://scholar.google.com) databases for the trial ID number, and (iii) searching these databases for the name of the trial's principal investigator in combination with the intervention and other potentially identifying information. Studies involving multiple types of pain, modalities, or targeted brain regions were counted in duplicate. For trials employing brain neuromodulation modalities, we also recorded the specific targets, target coordinates or location, and targeted side (left side, right side, bilateral, contralateral to pain, and ipsilateral to pain). This information was used to perform a connectomic mapping analysis of invasive and noninvasive brain targets for pain relief. Specifically, we investigated the functional networks associated with each brain target using a normative resting-state fMRI template to identify common networks underlying analgesic response $[21,22]$. A detailed description of this mapping analysis, which followed the methods outlined in a landmark study by Fox et al. [21-23] is provided in the online suppl. Methods.

\section{Results}

Our comprehensive search generated an initial list of 20,045 clinical trials in total (17,731 from the ICTRP, and 2,314 from the ClinicalTrials.gov, online suppl. Fig. S2). Removal of duplicate trials narrowed this trial count to 8,756 , while exclusion of unrelated trials via the multireviewer screening process resulted in a final selection of 


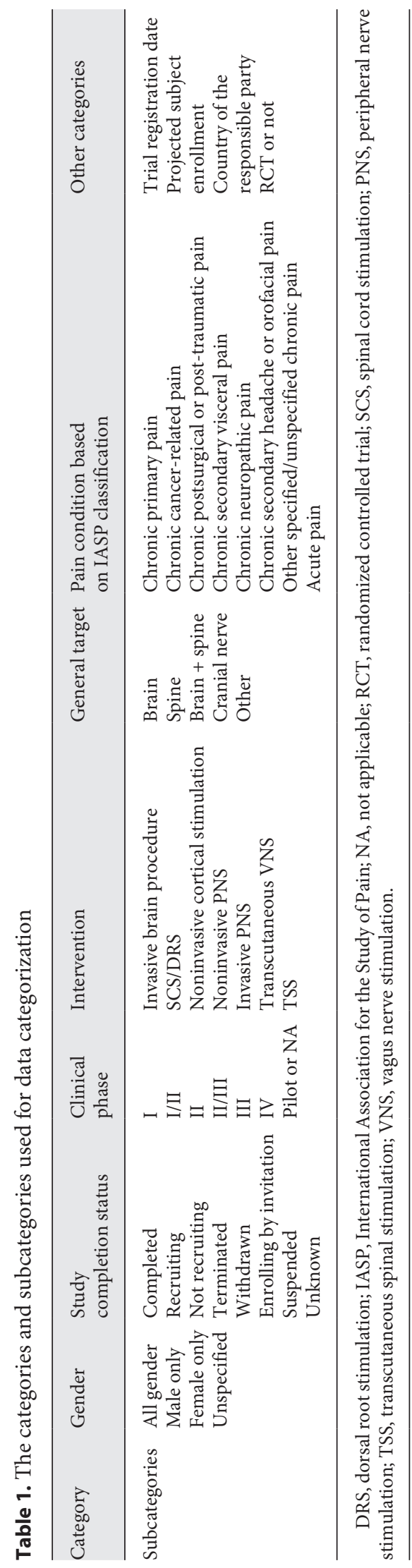

487 clinical trials related to neuromodulation for pain that were included in the analysis.

\section{Studies by Start Date and Status of Completion}

Over the past 2 decades, an increasing number of clinical trials have been registered each year (Fig. 1a). Approximately $50 \%$ of all clinical trial entries were registered within the last 5 years, indicating a recent rapid growth in research activity. Of the 451 trials (92.6\%) with a known status of completion, most were already completed (42.9\%) or currently recruiting $(24.8 \%)$. The remainder was either terminated $(8.4 \%)$, withdrawn $(2.9 \%)$, or suspended $(1.0 \%)$ (Table 2). The oldest trial still listed as actively recruiting was registered in December 2006 and is an open prospective randomized study to compare long-term efficacy between best medical practice with and without adjunctive SCS for chronic diabetic neuropathic pain. A total of 140 trials $(28.7 \%)$ were found to have associated published results. Of these trials, $65.5 \%$ revealed significant improvement in pain while $8.0 \%$ showed no significant difference. The rest (26.5\%) did not statistically analyze pain relief.

\section{Studies by Phase, Projected Enrollment, and}

Randomized Controlled Trial

With regard to projected enrollment, studies enrolling 11-50 participants predominated (53.3\%). Those enrolling $1-10,51-100,101-500$, and 501 or more participants accounted for $10.0,18.9,13.3$, and $2.2 \%$ of trials, respectively. Of the 90 trials that specified phases, phase II studies represented the largest proportion (33.3\%), followed by phase IV (28.9\%), III (12.2\%), II/III (11.1\%), I (7.8\%), and I/II (6.7\%). While phase IV trials were most prevalent between 2003 and 2015, phase II studies have surpassed them since 2016 (Fig. 1b). While $81.4 \%$ of phase I, I/II, and II studies projected to enroll $\leq 50$ subjects, $48.9 \%$ of phase II/III, III, and IV studies targeted to enroll $>50$ subjects (Table 3). Randomized controlled trials accounted for $65.9 \%$ of studies overall and specifically comprised over $70 \%$ of phase I/II (83.3\%), II/III (80.0\%), II (76.7\%), and III (72.7\%) trials (Fig. 1c). On the other hand, randomized controlled trials were relatively less represented amongst phase I (42.9\%) and 57.7\% in phase IV trials.

\section{Studies by Type of Pain Based on the International \\ Association for the Study of Pain Classification}

Categorized by the International Association for the Study of Pain classification, chronic primary pain (38.2\%) and chronic neuropathic pain (34.9\%) each represented over one-third of neuromodulation trials. These were followed in order by other specified/unspecified chronic 
pain $(8.9 \%)$, chronic secondary musculoskeletal pain $(4.5 \%)$, acute pain $(4.5 \%)$, chronic postsurgical or posttraumatic pain $(3.0 \%)$, chronic secondary visceral pain $(2.8 \%)$, chronic secondary headache or orofacial pain (1.7\%), and chronic cancer-related pain (1.6\%). Figure 1d shows the cumulative number of studies for each type of pain over time. Chronic primary pain overtook chronic neuropathic pain in 2007 to become the most common indication for neuromodulation trials.

\section{Studies by Modality and Target}

Noninvasive cortical stimulation (49.3\%) and spinal stimulation modalities (SCS/dorsal root stimulation [DRS]; 43.7\%) accounted for over $90 \%$ of trials (Table 4). Transcranial direct current stimulation $(60.0 \%)$ was the most common noninvasive cortical stimulation, followed by transcranial magnetic stimulation $(36.7 \%)$ and transcranial alternating current stimulation (2.0\%). By contrast, invasive brain stimulation $(2.8 \%)$, transcutaneous vagus nerve stimulation (1.8\%), noninvasive peripheral nerve stimulation (1.4\%), transcutaneous spinal stimulation $(0.8 \%)$, and invasive peripheral nerve stimulation $(0.4 \%)$ accounted for much smaller numbers of trials. Of the 14 clinical trials of invasive brain procedures, 1 investigated the efficacy of motor cortex stimulation using cortical electrodes, while the other 13 employed DBS. DBS targets included the posterior floor of the third ventricle, posteroinferior hypothalamus; bilateral ventral striatum/ anterior limb of the internal capsule, periaqueductal gray region (PAG), and anterior cingulate cortex (ACC) (Fig. 2). Figure 1e tracks the cumulative number of studies involving the 3 most prevalent modalities over time. While there were no registered DBS or SCS/DRS trials prior to 2002, SCS/DRS studies surpassed those involving noninvasive cortical stimulation in 2006 . However, noninvasive transcranial stimulation has rebounded to become the most common modality again since 2013. The number of studies on invasive brain procedures (primarily DBS) has also gradually increased but remains far lower than the number of noninvasive cortical stimulation and SCS/DRS trials. 188 of the 245 trials involving noninvasive transcranial stimulation specified the targeted brain regions. In these studies, the primary motor cortex (PMC) was the most frequent target (68.1\%), followed by the dorsolateral prefrontal cortex ([DLPFC]; 20.7\%), and primary sensory cortex ([PSC]; 3.2\%).

\section{Studies by Country of Origin}

More than $70 \%$ of trials were conducted primarily in North America (38.0\%) and Europe (33.3\%) (Fig. 3a). By

Clinical Trials for Pain Neuromodulation and Brain Networks country, USA fielded the largest number of trials (35.5\%), followed sequentially by Australia (8.0\%), Brazil (7.2\%), France (6.8\%), UK (5.3\%), Belgium (4.9\%), The Netherlands (4.9\%), Israel (2.9\%), Japan (2.7\%), and Canada (2.5\%) (Fig. 3b). These top 10 countries accounted for over $80 \%$ of all registered trials to date.

\section{Brain Network Mapping}

To permit connectomic network mapping, seeds were created for the following DBS targets: the posterior floor of the third ventricle; left side centromedian intralaminar parafascicular complex, nucleus accumbens, PAG, periventricular gray region (PVG), posterior limb of the internal capsule, posteroinferior hypothalamus, ventral posterolateral (VPL) nucleus; bilateral ACC, and ventral striatum/anterior limb of the internal capsule [24-33]. Cortical stimulation seeds were created for the subgenual ACC; left DLPFC, dorsal ACC, PMC, and PSC [34-38]. While some studies have examined subthalamic nucleus and globus pallidus internus DBS for Parkinson's diseaserelated pain, these 2 targets were excluded from the present study both because reports on this specific topic are limited and because of the possibility that these represent Parkinson's disease-specific targets [39, 40].

DBS targets tended to be consistently functionally connected to regions including the insula, pallidum, midbrain/brainstem regions such as PAG/PVG, red nuclei $(\mathrm{RN})$, and substantia nigra (SN), and multiple thalamic nuclei and nearby white matter (Fig. 4a). Brain regions consistently connected to noninvasive cortical stimulation targets included the PMC, medial PFC, DLPFC, ACC, supramarginal gyri, insula, caudate head, and ventral anterior, anteroventral, central median, and ventral posteromedial (VPM) nuclei (Fig. 4b). Brain regions that exhibited shared connectivity to both DBS and noninvasive cortical stimulation targets included the PMC, PSC, PFC, ACC, insula, caudate head, VPM, and VPL (Fig. 4c).

\section{Discussion}

We identified and analyzed a total of 487 publicly registered clinical trials related to neuromodulation for pain, finding evidence of an active and rapidly growing field dominated by chronic primary and neuropathic pain studies. We also performed a connectivity mapping analysis, seeding analgesic brain targets identified in our clinical trial search and the wider literature to probe common functional networks that may underlie pain relief. This analysis revealed several areas of common connectivity, 

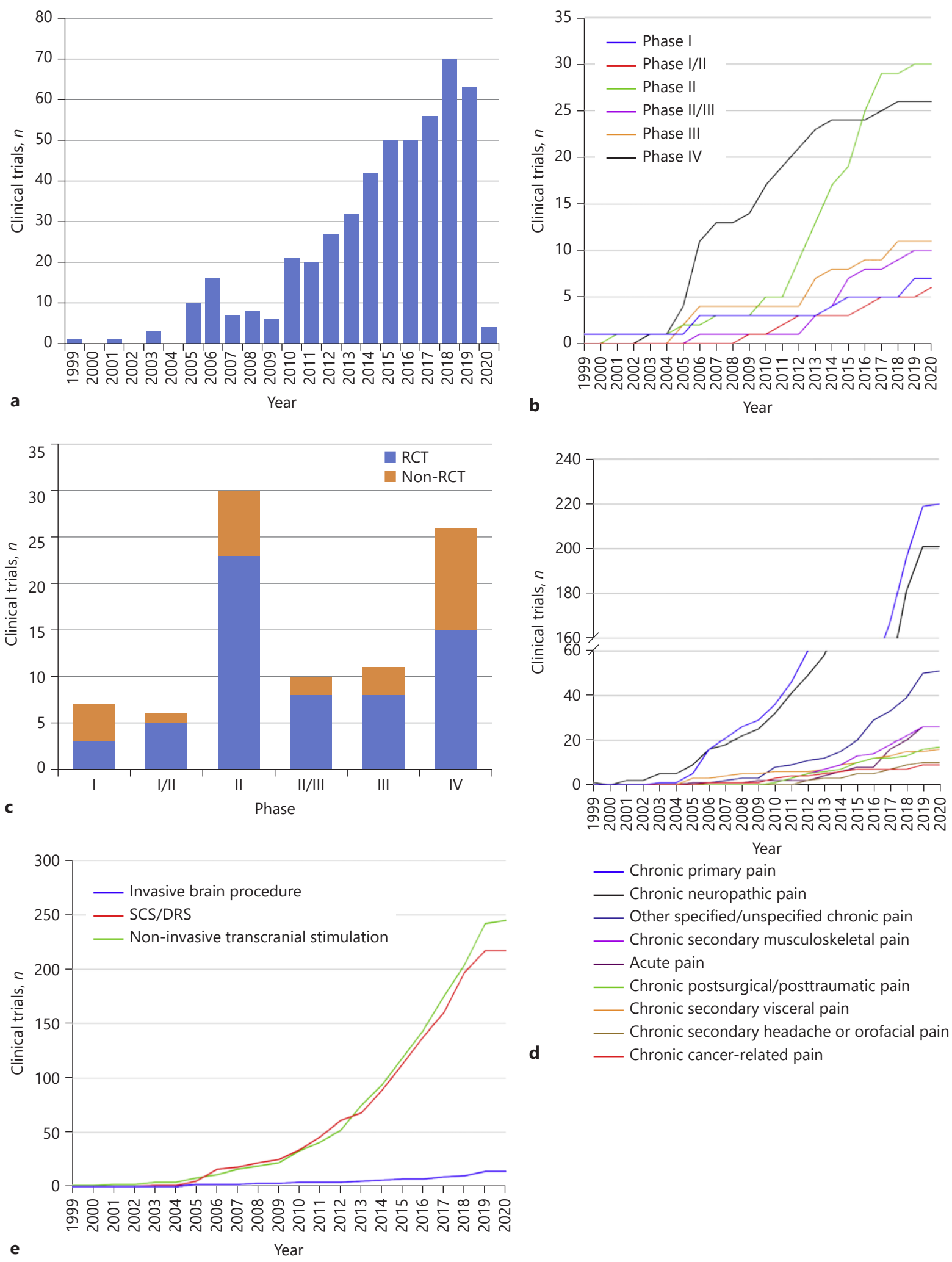
which could represent key regions in the pain matrix that subserve neuromodulatory intervention.

\section{Current Trends and Future Directions}

We observed a rapid increase in the number of pain neuromodulation trials registered in the last several years, suggesting an increased level of interest in this research topic. This uptick in research interest has likely been facilitated by the recent advances and developments in neurostimulation devices and medical imaging technologies [14, 41, 42].

Our results for the types of pain conditions treated with neuromodulation are in keeping with what is known about pain epidemiology. While previous studies have shown that chronic secondary pain due to osteoarthritis is the most common chronic pain condition $[3,6]$, these disorders often respond to orthopedic surgery and typically do not necessitate neuromodulatory treatment [43]. On the other hand, chronic primary pain and chronic neuropathic pain, which are also known to be highly prevalent $[3,5]$, are frequently resistant to standard treatments [44, 45]. It is not surprising, then, that these conditions were found to predominate in neurostimulation trials.

In our analysis of clinical trials by country of origin, we found evidence of worldwide participation in pain neu-

Table 2. The status of completion of registered clinical trials

\begin{tabular}{lrc}
\hline Status & $n$ & $\%$ \\
\hline Completed & 209 & 42.9 \\
Recruiting & 121 & 24.8 \\
Not recruiting & 56 & 11.5 \\
Terminated & 41 & 8.4 \\
Withdrawn & 14 & 2.9 \\
Enrolling by invitation & 5 & 1.0 \\
Suspended & 5 & 1.0 \\
Unknown & 36 & 7.4 \\
\hline Total & 487 & 100 \\
\hline
\end{tabular}

Fig. 1. a Number of clinical trials over years. The bar graph shows an overall increase of registered trials, with the trials in the last 5 years accounting for approximately half of all entries. b Cumulative number of clinical trials by phase over years. Phase IV trials were the most common from 2005 to 2015 . However, phase II trials have been the most common since they surpassed phase IV in 2016. c Clinical trials by phase. RCTs account for over $70 \%$ in phase I/II, II, II/III, and III trials, while $57.1 \%$ of phase I and $42.3 \%$ of phase IV were non-RCTs. d Cumulative number of clinical trials by pain classification over years. While all classifications of pain romodulation research. However, the top 10 countries accounted for over $80 \%$ of all trials, with the United States fielding a disproportionate percentage of this number. There have been multiple publications on the prevalence of chronic pain in each of these 10 countries, possibly indicating the great interest in pain in those countries [3-6, 46-51], despite their prevalence of chronic pain (median: $27.7 \%$, interquartile range: $20.5-36.9$ ) being fairly similar to the worldwide prevalence $(21.5 \%)$ reported by the World Health Organization [52]. Given that the topranking countries all have high gross domestic products, it is likely that socioeconomic conditions influence the degree to which countries invest in and prioritize pain neuromodulation research [53]. Indeed, many lesswealthy countries have traditionally prioritized research into alternative prevalent conditions, including infectious diseases [54-56]. The availability of resources necessary to conduct neuromodulation trials, including the actual devices, qualified experts and physicians, and essential infrastructure, is a related bottleneck on more evenly distributed research in this field.

With regard to treatment modalities, noninvasive cortical stimulation is technically easier to perform than invasive brain procedures and requires less multidisciplinary expertise and infrastructure $[57,58]$. This can explain the considerably higher number of noninvasive cortical stimulation trials relative to invasive procedures found here.

\section{Network Connectivity of Neuromodulation Targets for Pain Relief}

Our connectomic mapping analysis of DBS and noninvasive cortical stimulation targets revealed multiple brain regions, namely PMC, PFC (medial PFC and DLPFC), PSC, ACC (dorsal and subgenual), insula, and VPM/ VPL, that shared meaningful functional connectivity with both types of targets. Of note, many of these regions have been shown through previous research to be activated by pain stimulation or painful conditions, support-

show growth in the number of studies over time, studies on chronic primary pain and chronic neuropathic pain demonstrate a remarkable increase, having been the top 2 since 2003. e Cumulative number of clinical trials of the top 3 modalities over years. The number of trials has grown in all the top 3 modalities over time. However, SCS/DRS and noninvasive cortical stimulation have been the top 2 modalities since 2003, showing a remarkable growth compared to the third most common modality, invasive brain procedure. DRS, dorsal root stimulation; SCS, spinal cord stimulation; RCTs, randomized controlled trials. 
Fig. 2. Neuromodulation modalities and targets in clinical trials. Numbers mean trial counts. Note that only targets specified in the trials were counted and listed. Figure reproduced with permission of the copyright owner. ACC, anterior cingulate cortex; dACC, dorsal anterior cingulate cortex; ALIC, anterior limb of the internal capsule; DBS, deep brain stimulation; DLPFC, dorsolateral prefrontal cortex; MPFC, medial prefrontal cortex; OFC, orbitofrontal cortex; PAG, periaqueductal gray region; PFC, prefrontal cortex; PMC, primary motor cortex; PNS, peripheral nerve stimulation; PSC, primary sensory cortex; PVG, periventricular gray region; SCS, spinal cord stimulation; sgACC, subgenual anterior cingulate cortex; SSC, secondary sensory cortex; TENS, transcutaneous electric nerve stimulation; TSS, transcutaneous spinal stimulation; VNS, vagus nerve stimulation; VS, ventral striatum.

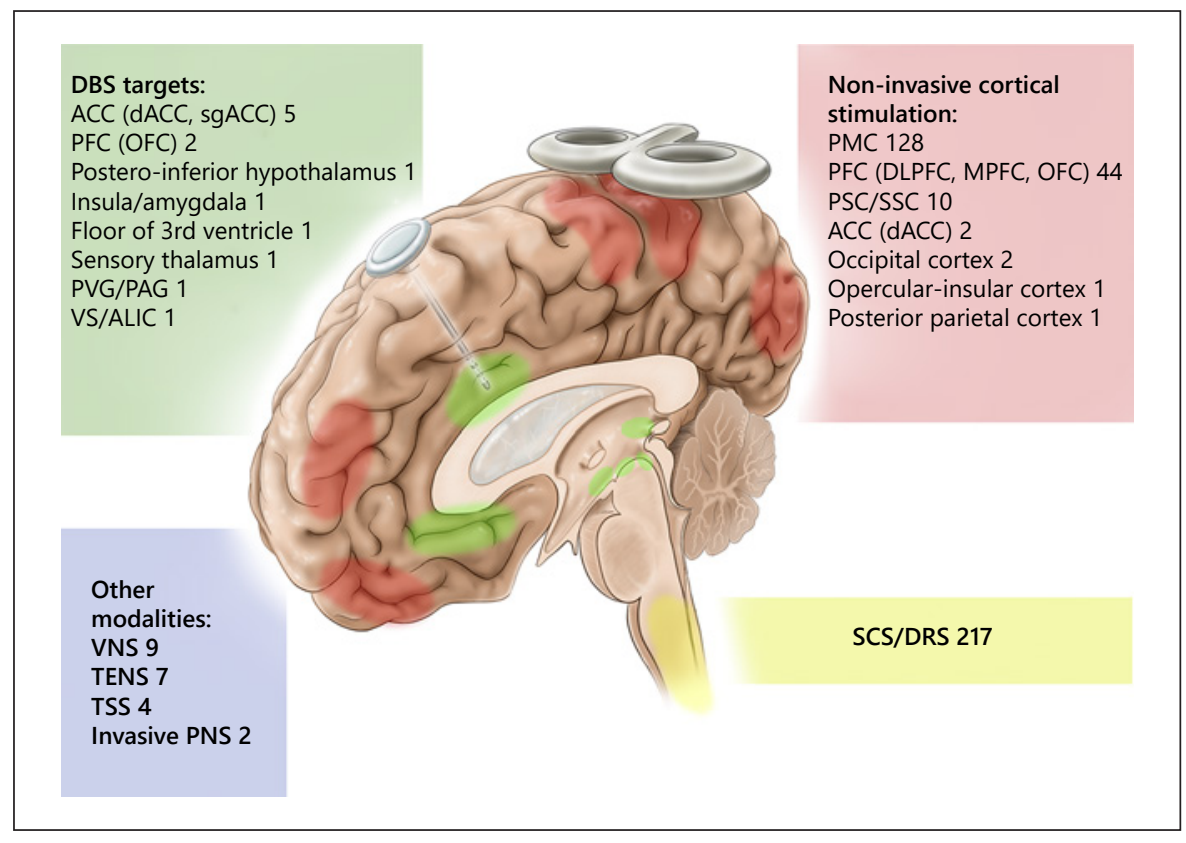

Table 3. Number of enrolled participants by phase

\begin{tabular}{lllrrrrrrr}
\hline Enrolled participants & \multicolumn{3}{l}{ Studies, $n$-phase } & & \multirow{2}{*}{ Total } & $\begin{array}{l}\text { Percent of total } \\
\text { studies }(\%)\end{array}$ \\
\cline { 2 - 7 } & I & I/II & II & II/III & III & IV & & \\
\hline $501-$ & 0 & 1 & 1 & 0 & 0 & 0 & 2 & 2.2 \\
$101-500$ & 0 & 0 & 3 & 1 & 2 & 6 & 12 & 13.3 \\
$51-100$ & 0 & 0 & 3 & 4 & 7 & 3 & 17 & 18.9 \\
$11-50$ & 5 & 4 & 21 & 4 & 2 & 12 & 48 & 53.3 \\
$1-10$ & 2 & 1 & 1 & 0 & 0 & 5 & 9 & 10.0 \\
0 & 0 & 0 & 1 & 1 & 0 & 0 & 2 & 2.2 \\
\hline Total & 7 & 6 & 30 & 10 & 11 & 26 & 90 & 100 \\
\hline
\end{tabular}

Table 4. Number of clinical trials by modality and actively recruiting trials

\begin{tabular}{lcc}
\hline Treatment modality & $\begin{array}{l}\text { Trials, } \\
n(\%)^{*}\end{array}$ & $\begin{array}{l}\text { Actively recruiting, } \\
n(\%)^{* *}\end{array}$ \\
\hline Noninvasive cortical stimulation & $245(49.3)$ & $60(24.5)$ \\
SCS/DRS & $217(43.7)$ & $61(24.9)$ \\
Invasive brain procedure & $14(2.8)$ & $4(28.6$ \\
Transcutaneous VNS & $9(1.8)$ & $0(0)$ \\
TENS/noninvasive transcutaneous electrical/magnetic stimulation & $7(1.4)$ & $1(14.3)$ \\
TSS & $4(0.8)$ & $1(25.0)$ \\
Invasive PNS & $1(0.2)$ & $0(0)$ \\
Total & 497 & 127 \\
\hline
\end{tabular}

DRS, dorsal root stimulation; SCS, spinal cord stimulation; TENS, transcutaneous electric nerve stimulation; VNS, vagus nerve stimulation; PNS, peripheral nerve stimulation; TSS, transcutaneous spinal stimulation. ${ }^{*}$ Trials were counted in duplicate. Values in parentheses are percentages of total trials. ${ }^{\star \star}$ Actively recruiting trials include those enrolling participants by invitation. Values in parentheses are percentages of each modality. 
Fig. 3. Clinical trials by country of origin. a North America and Europe represent the vast majority of trials. Of note, 6 of the top 10 countries belong to North America and Europe. b There has been a steady growth in the number of studies in all the top 10 countries, especially in recent years. Notably, the United States has shown tremendous growth since 2005 .

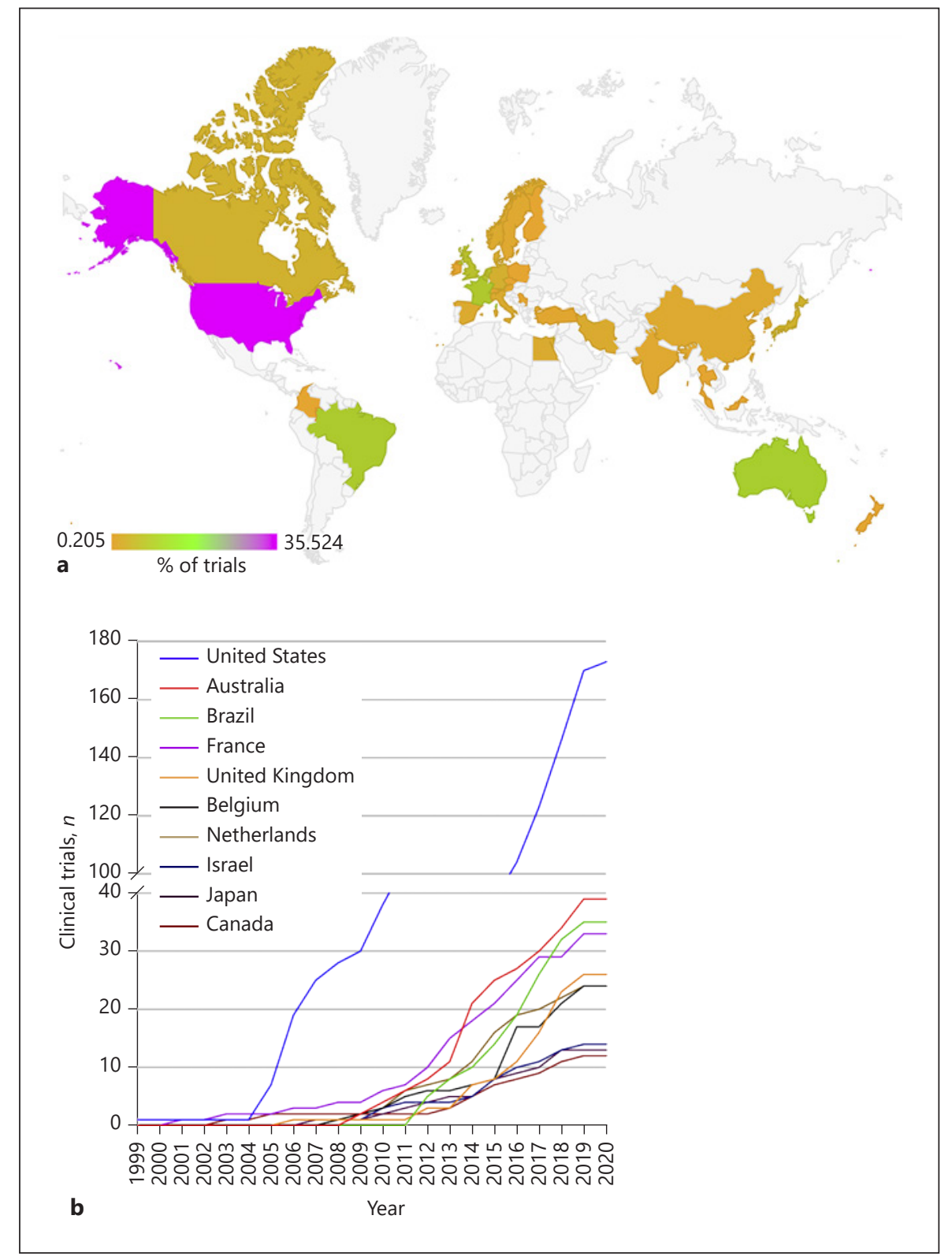

ing the reliability of our results [59-63]. For instance, Dunckley et al. [59] demonstrated in an fMRI study that both visceral and somatic pain activates areas such as the PAG, SN, and RN. Another fMRI study by Gracely et al. [60] showed a significant signal increase in the PMC, ACC, ventral anterior nucleus and ventral lateral nucleus of the thalamus, caudate nucleus, globus pallidus, and insula by painful pressure stimuli. Activation was apparent in the ACC, DLPFC, thalamus, and caudate nucleus after painful muscle and bone stimulation in an fMRI study by Maeda et al. [61]. Acute and chronic pain activates the $\mathrm{PFC}$, and its activation is associated with increased activ- ity of the PAG [63]. Moreover, most of these regions form the core of pain processing $[15,64]$.

Many of the common areas identified in our network connectivity analysis have themselves been stimulated for pain relief. The inter-target connectedness of PAG/PVG and VPM/VPL thalamus is consistent with the clinical evidence, as both regions are major targets for pain neuromodulation $[65,66]$. Previous papers, including a meta-analysis and systematic review [65-67], indicate that DBS of the PAG/PVG is associated with higher rates of long-term pain alleviation than DBS of the VPM/VPL. However, while PAG/PVG DBS appears to be particu- 


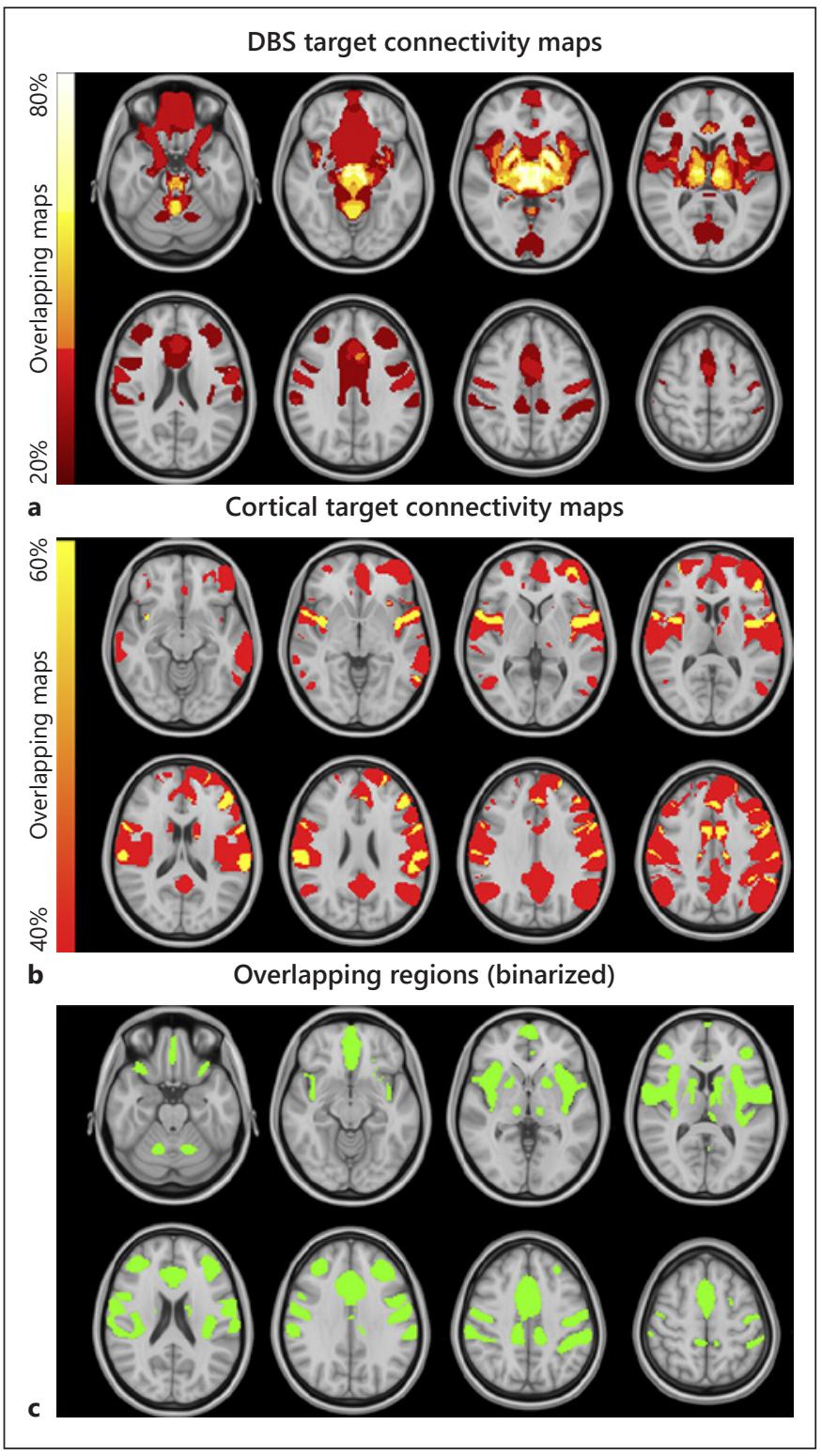

Fig. 4. Functional connectivity networks for pain neuromodulation. a Voxels associated with pain neuromodulation by DBS were significantly $\left(p_{\text {Bonferroni }}<0.05\right)$ correlated with and well overlapping in regions including the GPe, insula, $\mathrm{RN}, \mathrm{SN}, \mathrm{PAG} / \mathrm{PVG}$, and multiple thalamic nuclei. $\mathbf{b}$ Correlated regions of noninvasive cortical stimulation overlapped in the PMC, MPFC, DLPFC, dACC, sgACC, supramarginal gyri, insula, caudate head, and VA, AV, CM, and VPM thalamic nuclei. c Overlapping regions between the summed maps (a, b) included the PMC, PSC, dACC, sgACC, insula, caudate head, VPM, and VPL. AV, anteroventral nucleus; CM, centromedian nucleus; dACC, dorsal anterior cingulate cortex; DLPFC, dorsolateral prefrontal cortex; GPe, globus pallidus externus; MPFC, medial prefrontal cortex; PAG, periaqueductal gray region; PMC, primary motor cortex; PVG, periventricular gray region; PSC, primary sensory cortex; RN, red nucleus; sgACC, subgenual anterior cingulate cortex; $\mathrm{SN}$, substantia nigra; VA, ventral anterior; VPL, ventral posterolateral; VPM, ventral posteromedial; DBS, deep brain stimulation. larly useful for treating chronic nociceptive pain, combined DBS of the PAG/PVG and VPM/VPL may deliver better outcomes for neuropathic conditions. Stimulation of PMC and DLPFC using noninvasive techniques has also been demonstrated to provide pain relief [68-71], consistent with their established connections with key pain processing structures $[63,72,73]$.

Other overlapping brain regions in our results included the insula, RN, SN, putamen, and ACC. Among these regions, the insula, $\mathrm{SN}$, putamen, and ACC are included in the abovementioned connectivity network of pain. There have been some studies showing pain relief by stimulating these areas directly [74-81]. In 1 study of 22 chronic neuropathic pain patients, bilateral dorsal ACCDBS was associated with a $43 \%$ decrease in pain scores at 1 year [75]. On the other hand, transcranial direct current stimulation of the insular cortex evoked painful sensation in 14 of 43 participants in a human study [82]. However, high-frequency stimulation of the posterior insula raises patients' thermal pain thresholds [83]. Further, a recent study in rats has suggested that stimulation of the posterior insula provides pain alleviation by modulating GABAergic signaling [84]. These findings indicate that the insula may be a potential target for pain neuromodulation by adjusting stimulation parameters and specific target locations. While, to our knowledge, there have been no publications on pain relief by putaminal stimulation, the putamen may not be adequate as a target because some reports suggest that putaminal stimulation causes involuntary movements and amnesia [74, 78]. Some animal experiments demonstrated that stimulation of the caudate nucleus and SN can reduce pain reactivity, but reactivity for only acute pain was investigated in all these studies [76, 77, 79-81]. Despite the absence of evidence on chronic pain, the SN and caudate nucleus may be potential targets for pain relief. Meanwhile, RN stimulation has been shown to induce acute antinociception in rats [85], while other rodent work indicated RN participates in the maintenance of neuropathic pain through the upregulation of interleukin-6 [86].

\section{Limitations}

This study was limited by its reliance on the clinical trial registries. While we sought to reduce geographical bias by searching both ClinicalTrials.gov (operated and maintained by the United States National Library of Medicine) and the World Health Organization's ICTRP database, we were only able to detect trials that had been publicly registered. However, this was somewhat mitigated by the increasing rate of clinical trial registration in recent
Yamamoto et al. 
years [87]. Another limitation was the fact that our connectivity mapping analysis was not able to incorporate modalities that target extracranial structures, such as SCS and vagus nerve stimulation. Investigating the networks engaged by nonbrain targets would require more sophisticated approaches and could be a valuable pursuit for future research.

\section{Conclusion}

We analyzed the current state of clinical trials for pain neuromodulation and explored the common brain networks underlying pain relief using connectomic mapping analysis. Our analysis of registered clinical trials indicated that human research for pain neuromodulation is a rapidly growing field and highlighted the current preeminence of transcranial and extracranial stimulation modalities. Our connectomic network analysis reinforced existing knowledge of the pain matrix, identifying both well-described hubs (such as PAG/PVG, VPM/VPL thalamus, and ACC) and more obscure structures (like SN and caudate nucleus) that might warrant further examination as potential stimulation targets for pain relief.

\section{Conflict of Interest Statement}

A.M.L. is the cofounder of Functional Neuromodulation (a DBS-related company), is a consultant for Medtronic, Boston Scientific, and Abbott (companies that manufacture DBS devices), is the editor in chief of Stereotactic and Functional Neurosurgery, and holds intellectual property in the field of DBS. S.K. and M.H. are editorial board members of Stereotactic and Functional Neurosurgery. The other authors report no conflicts of interest.

\section{Funding Sources}

This study was supported by the Canadian Institutes of Health Research (reference \# 164235: G.J.B.E.). The funding source had no role in the study design, data collection, data analysis, data interpretation, writing of the report, or decision to submit for publication.

\section{Author Contributions}

Study design: K.Y., G.J.B.E., A.L., J.G., and A.M.L. Writing and figure preparation: K.Y., G.J.B.E., M.E.B., A.Z., and C.S. prepared the initial draft of the manuscript and figures; K.Y., G.J.B.E., A.Z., A.L., J.G., A.B., S.K., and A.M.L. critically revised the draft; all authors reviewed and edited the manuscript and approved the submitted version. Analysis: K.Y., G.J.B.E., M.E.B., and A.L. performed analyses of data. Study supervision: A.M.L.

\section{Availability of Data and Material}

Ethics approval was not required for this study because it did not involve any human subjects.
All data generated or analyzed during this study are included in this article or its online suppl. material files. Further enquiries can be directed to the corresponding author.

\section{References}

1 Pizzo P. Relieving pain in America: a blueprint for transforming prevention, care, education, and research. Washington (DC): National Academies Press; 2011.

2 Turk DC. Clinical effectiveness and cost-effectiveness of treatments for patients with chronic pain. Clin J Pain. 2002 Nov-Dec; 18(6):355-65.

3 Breivik H, Collett B, Ventafridda V, Cohen $\mathrm{R}$, Gallacher D. Survey of chronic pain in Europe: prevalence, impact on daily life, and treatment. Eur J Pain. 2006;10(4): 287.

4 Dahlhamer J, Lucas J, Zelaya C, Nahin R, Mackey S, DeBar L, et al. Prevalence of chronic pain and high-impact chronic pain among adults: United States, 2016. MMWR Morb Mortal Wkly Rep. 2018;67(36):10016.

5 Johannes CB, Le TK, Zhou X, Johnston JA, Dworkin RH. The prevalence of chronic pain

Clinical Trials for Pain Neuromodulation and Brain Networks in United States adults: results of an internetbased survey. J Pain. 2010 Nov;11(11):12309.

6 Schopflocher D, Taenzer P, Jovey R. The prevalence of chronic pain in Canada. Pain Res Manag. 2011 Nov-Dec;16(6):44550.

7 Gustavsson A, Bjorkman J, Ljungcrantz C, Rhodin A, Rivano-Fischer M, Sjolund KF, et al. Socio-economic burden of patients with a diagnosis related to chronic pain: register data of 840,000 Swedish patients. Eur J Pain. 2012; 16(2):289-99.

8 Raftery MN, Ryan P, Normand C, Murphy AW, De La Harpe D, McGuire BE. The economic cost of chronic noncancer pain in Ireland: results from the PRIME study, part 2. J Pain. 2012;13(2):139-45.

9 Mao J, Gold MS, Backonja MM. Combination drug therapy for chronic pain: a call for more clinical studies. J Pain. 2011;12(2):157-66.
10 Derry S, Wiffen PJ, Kalso EA, Bell RF, Aldington D, Phillips T, et al. Topical analgesics for acute and chronic pain in adults: an overview of cochrane reviews. Cochrane Database Syst Rev. 2017.

11 Reinecke H, Weber C, Lange K, Simon M, Stein C, Sorgatz H. Analgesic efficacy of opioids in chronic pain: recent meta-analyses: opioids in chronic pain. Br J Pharmacol. 2015 Jan;172(2):324-33.

12 Pergolizzi J, Ahlbeck K, Aldington D, Alon E, Coluzzi F, Dahan A, et al. The development of chronic pain: physiological change necessitates a multidisciplinary approach to treatment. Curr Med Res Opin. 2013;29(9):1127-35.

13 Kumar K, Rizvi S. Historical and present state of neuromodulation in chronic pain. Curr Pain Headache Rep. 2014;18(1):387.

14 Gildenberg PL. History of electrical neuromodulation for chronic pain. Pain Med. 2006; 7(Suppl 1):S7-13. 
15 Caylor J, Reddy R, Yin S, Cui C, Huang M, Huang C, et al. Spinal cord stimulation in chronic pain: evidence and theory for mechanisms of action. Bioelectron Med. 2019;5(1): $1-41$.

16 Green AL, Aziz TZ. Neuromodulation for intractable pain. Brain Sci. 2020;10(5):10-2.

17 Harmsen IE, Elias GJB, Beyn ME, Boutet A, Pancholi A, Germann J, et al. Clinical trials for deep brain stimulation: current state of affairs. Brain Stimulation. 2020 Apr;13(2):37885.

18 Harmsen IE, Hasanova D, Elias GJ, Boutet A, Neudorfer C, Loh A, et al. Trends in clinical trials for spinal cord stimulation. Stereotact Funct Neurosurg. 2020;99(2):123.

19 Mansouri A, Beyn ME, Pancholi A, Chow CT, Wang R, Boutet A, et al. Evolution of the neurosurgeon's role in clinical trials for glioblastoma: a systematic overview of the clinicaltrials. Gov Database Neurosurgery.. 2021 May: nyab169.

20 Darby RR, Joutsa J, Fox MD. Network localization of heterogeneous neuroimaging findings. Brain. 2019;142(1):70-9.

21 Fox MD, Buckner RL, Liu H, Chakravarty MM, Lozano AM, Pascual-Leone A. Restingstate networks link invasive and noninvasive brain stimulation across diverse psychiatric and neurological diseases. Proc Natl Acad Sci U S A. 2014;111(41):E4367-75.

22 Fox MD, Liu H, Pascual-Leone A. Identification of reproducible individualized targets for treatment of depression with TMS based on intrinsic connectivity. NeuroImage. 2013;66: $151-60$.

23 Elias GJB, Boutet A, Joel SE, Germann J, Gwun D, Neudorfer C, et al. Probabilistic mapping of deep brain stimulation: insights from 15 years of therapy. Ann Neurol. 2021; 89(3):426-43.

24 Boccard SGJ, Fitzgerald JJ, Pereira EAC, Moir L, Van Hartevelt TJ, Kringelbach ML, et al. Targeting the affective component of chronic pain: a case series of deep brain stimulation of the anterior cingulate cortex. Neurosurgery. 2014;74(6):628-35.

25 Chabardès $S$, Carron R, Seigneuret E, Torres N, Goetz L, Krainik A, et al. Endoventricular deep brain stimulation of the third ventricle: proof of concept and application to cluster headache. Neurosurgery. 2016;79(6):806-15.

26 Fontaine D, Lazorthes Y, Mertens P, Blond S, Géraud G, Fabre N, et al. Safety and efficacy of deep brain stimulation in refractory cluster headache: a randomized placebo-controlled double-blind trial followed by a 1-year open extension. J Headache Pain. 2010;11(1):2331.

27 Franzini A, Messina G, Levi V, D’Ammando A, Cordella R, Moosa S, et al. Deep brain stimulation of the posterior limb of the internal capsule in the treatment of central poststroke neuropathic pain of the lower limb: case series with long-term follow-up and literature review. J Neurosurg. 2020;133(3): $830-8$.
28 Kalani Y, Kalani MA, Sabelman EE, Bernstien I, Heit G. Deep brain stimulation of the periaqueductal gray for treatment of nociceptive pain: tryptophan loading and the serotonergic circuit of pain. Cureus. 2012;2(1):1-8.

29 Krauss JK, Pohle T, Weigel R, Burgunder JM. Deep brain stimulation of the centre medianparafascicular complex in patients with movement disorders. J Neurol Neurosurg Psychiatry. 2002;72(4):546-8.

30 Machado A, Haber S, Sears N, Greenberg B, Malone D, Rezai A. Functional topography of the ventral striatum and anterior limb of the internal capsule determined by electrical stimulation of awake patients. Clin Neurophysiol. 2009;120(11):1941-8.

31 Mallory GW, Abulseoud O, Hwang SC, Gorman DA, Stead SM, Klassen BT, et al. The nucleus accumbens as a potential target for central poststroke pain. Mayo Clin Proc. 2012; 87(10):1025-31.

32 Richardson DE, Akil H. Pain reduction by electrical brain stimulation in man. I. Acute administration in periaqueductal and periventricular sites. J Neurosurg. 1977;47(2):178-83.

33 Young RF, Chambi VI. Pain relief by electrical stimulation of the periaqueductal and periventricular gray matter: evidence for a nonopioid mechanism. J Neurosurg. 1987;66(3): 364-71.

34 Fitzgibbon BM, Hoy KE, Knox LA, Guymer EK, Littlejohn G, Elliot D, et al. Evidence for the improvement of fatigue in fibromyalgia: a 4-week left dorsolateral prefrontal cortex repetitive transcranial magnetic stimulation randomized-controlled trial. Eur J Pain. 2018 Aug;22(7):1255-67.

35 Grundmann L, Rolke R, Nitsche MA, Pavlakovic G, Happe S, Treede R-D, et al. Effects of transcranial direct current stimulation of the primary sensory cortex on somatosensory perception. Brain Stimulation. 2011 Oct;4(4): 253-60.

36 Jafarzadeh A, Ehsani F, Yosephi MH, Zoghi $\mathrm{M}$, Jaberzadeh S. Concurrent postural training and M1 anodal transcranial direct current stimulation improve postural impairment in patients with chronic low back pain. J Clin Neurosci. 2019 Oct;68:224-34.

37 Magis D, D’Ostilio K, Lisicki M, Lee C, Schoenen J. Anodal frontal tDCS for chronic cluster headache treatment: a proof-of-concept trial targeting the anterior cingulate cortex and searching for nociceptive correlates. J Headache Pain. 2018 Dec;19(1):72.

38 Mariano TY, Burgess FW, Bowker M, Kirschner J, Van't Wout-Frank M, Jones RN, et al. Transcranial direct current stimulation for affective symptoms and functioning in chronic low back pain: a pilot double-blinded, randomized, placebo-controlled trial. Pain Med. 2019 Jun;20(6):1166-77.

39 Gong S, Xu M, Tao Y, Jin H, Liu Y, Sun X, et al. Comparison of subthalamic nucleus and globus pallidus internus deep brain stimulation surgery on parkinson disease-related pain. World Neurosurg. 2020;135:e94-9.
40 Loher TJ, Burgunder JM, Weber S, Sommerhalder R, Krauss JK. Effect of chronic pallidal deep brain stimulation on off period dystonia and sensory symptoms in advanced Parkinson's disease. J Neurol Neurosurg Psychiatry. 2002;73(4):395-9.

41 Hariz M, Amadio JP. The new era of neuromodulation. AMA J Ethics. 2015;17(1):74-81.

42 Krames ES, Hunter Peckham P, Rezai A, Aboelsaad F. What is neuromodulation? Neuromodulation. 2009:3-8.

43 Sinusas K. Osteoarthritis: diagnosis and treatment. Am Fam Physician. 2012;85(1):49-56.

44 Bonezzi C, Fornasari D, Cricelli C, Magni A, Ventriglia G. Not all pain is created equal: basic definitions and diagnostic work-up. Pain Ther. 2020 Dec;9(Suppl 1):1-15.

45 Tao Z-Y, Wang P-X, Wei S-Q, Traub RJ, Li J-F, Cao D-Y. The role of descending pain modulation in chronic primary pain: potential application of drugs targeting serotonergic system. Neural Plasticity. 2019 Dec2019; 2019:1-16.

46 Blyth FM, March LM, Brnabic AJ, Jorm LR Williamson M, Cousins MJ. Chronic pain in Australia: a prevalence study. Pain. 2001; 89(2-3):127-34.

47 Carvalho RC, Maglioni CB, Machado GB, Araújo JE, Silva JRT, Silva ML. Prevalence and characteristics of chronic pain in Brazil: a national internet-based survey study. Braz J Pain. 2018;1(4):331-8.

48 Inoue S, Kobayashi F, Nishihara M, Arai YC, Ikemoto T, Kawai T, et al. Chronic Pain in the Japanese community-prevalence, characteristics and impact on quality of life. PLoS One. 2015;10(6): $\mathrm{e} 0129262$.

49 Moulin DE, Clark AJ, Speechley M, MorleyForster PK. Chronic pain in Canada: prevalence, treatment, impact and the role of opioid analgesia. Pain Res Manag. 2002;7(4) $179-84$.

50 Souza JB, Grossmann E, Perissinotti DMN, Oliveira Junior JO, Fonseca PRBd, Posso Id. Prevalence of chronic pain, treatments, perception, and interference on life activities: Brazilian population-based survey. Pain Res Manag. 2017;2017:1-9.

51 Takura T, Ushida T, Kanchiku T, Ebata N, Fujii $\mathrm{K}$, DiBonaventura $\mathrm{M}$, et al. The societal burden of chronic pain in Japan: an internet survey. J Orthop Sci. 2015;20(4):750-60.

52 Gureje O, Von Korff M, Simon GE, Gater R. Persistent pain and well-being: a World Health Organization study in primary care. JAMA. 1998;280(2):147-51.

53 The World Bank. GDP Ranking [Internet]. [cited 2021 Mar 31]. Available from:

54 A de-Graft A, Unwin N, Agyemang C, Allotey P, Campbell C, Arhinful D. Tackling Africa's chronic disease burden: from the local to the global. Glob Health. 2010;6(1):5.

55 Helleringer S. Understanding the adolescent gap in HIV testing among clients of antenatal care services in West and Central African countries. AIDS Behav. 2017;21(9):276073. 
56 Paudyal N, Anihouvi V, Hounhouigan J, Matsheka MI, Sekwati-Monang B, AmoaAwua W, et al. Prevalence of foodborne pathogens in food from selected African countries: a meta-analysis. Int J Food Microbiol. 2017 May;249:35-43.

57 Fregni F, Freedman S, Pascual-Leone A. Recent advances in the treatment of chronic pain with non-invasive brain stimulation techniques. Lancet Neurol. 2007 Feb;6(2): $188-91$.

58 O'Connell NE, Marston L, Spencer S, DeSouza LH, Wand BM. Non-invasive brain stimulation techniques for chronic pain. Cochrane Database Syst Rev. 2018;3(3):CD008208.

59 Dunckley P, Wise RG, Fairhurst M, Hobden P, Aziz Q, Chang L, et al. A Comparison of visceral and somatic pain processing in the human brainstem using functional magnetic resonance imaging. J Neurosci. 2005 Aug; 25(32):7333-41.

60 Gracely RH, Petzke F, Wolf JM, Clauw DJ. Functional magnetic resonance imaging evidence of augmented pain processing in fibromyalgia. Arthritis Rheum. 2002 May;46(5): 1333-43.

61 Maeda L, Ono M, Koyama T, Oshiro Y, Sumitani M, Mashimo T, et al. Human brain activity associated with painful mechanical stimulation to muscle and bone. J Anesth. 2011 Aug;25(4):523-30.

62 Martel M, Harvey MP, Houde F, Balg F, Goffaux P, Léonard G. Unravelling the effect of experimental pain on the corticomotor system using transcranial magnetic stimulation and electroencephalography. Exp Brain Res. 2017 Apr;235(4):1223-31.

63 Ong WY, Stohler CS, Herr DR. Role of the prefrontal cortex in pain processing. Mol Neurobiol. 2019 Feb;56(2):1137-66.

64 Shirvalkar P, Veuthey TL, Dawes HE, Chang EF. Closed-loop deep brain stimulation for refractory chronic pain. Front Comput Neurosci. 2018;12:18

65 Bittar RG, Kar-Purkayastha I, Owen SL, Bear RE, Green A, Wang S, et al. Deep brain stimulation for pain relief: a meta-analysis. J Clin Neurosci. 2005 Jun;12(5):515-9.

66 Boccard SG, Pereira EA, Aziz TZ. Deep brain stimulation for chronic pain. J Clin Neurosci. 2015 Oct;22(10):1537-43.
67 Elias GJB, Loh A, Gwun D, Pancholi A, Boutet A, Neudorfer C, et al. Deep brain stimulation of the brainstem. Brain. 2020:awaa374.

68 Henssen DJHA, Kurt E, van Cappellen van Walsum AM, Arnts I, Doorduin J, Kozicz T, et al. Long-term effect of motor cortex stimulation in patients suffering from chronic neuropathic pain: an observational study. PLoS One. 2018 Jan;13(1):e0191774.

69 Radic JA, Beauprie I, Chiasson P, Kiss ZH, Brownstone RM. Motor cortex stimulation for neuropathic pain: a randomized crossover trial. Can J Neurol Sci. 2015;42(6):401-9.

70 Seminowicz DA, de Martino E, Schabrun SM Graven-Nielsen T. Left dorsolateral prefrontal cortex repetitive transcranial magnetic stimulation reduces the development of longterm muscle pain. Pain. 2018 Dec;159(12): 2486-92.

71 Tanwar S, Mattoo B, Kumar U, Bhatia R. Repetitive transcranial magnetic stimulation of the prefrontal cortex for fibromyalgia syndrome: a randomised controlled trial with 6-months follow up. Adv Rheumatol. 2020; 60(1):34.

72 Maarrawi J, Peyron R, Mertens P, Costes N, Magnin M, Sindou M, et al. Motor cortex stimulation for pain control induces changes in the endogenous opioid system. Neurology. 2007 Aug;69(9):827-34.

73 Peyron R, Faillenot I, Mertens P, Laurent B, Garcia-Larrea L. Motor cortex stimulation in neuropathic pain. Correlations between analgesic effect and hemodynamic changes in the brain. A PET study. NeuroImage. 2007 Jan; 34(1):310-21.

74 Lorenzini CGA, Baldi E, Bucherelli C, Sacchetti B, Tassoni G. Neural topography and chronology of memory consolidation: a review of functional inactivation findings. Neurobiol Learn Mem. 1999 Jan;71(1):1-18

75 Boccard SGJ, Prangnell SJ, Pycroft L, Cheeran B, Moir L, Pereira EAC, et al. Long-term results of deep brain stimulation of the anterior cingulate cortex for neuropathic pain. World Neurosurg. 2017 Oct;106:625-37.

76 Jurna I, Heinz G, Blinn G, Nell T. The effect of substantia negra stimulation and morphine on alpha-motoneurones and the tail-flick response. Eur J Pharmacol. 1978;51(3):239-50.
77 Lineberry CG, Vierck CJ. Attenuation of pain reactivity by caudate nucleus stimulation in monkeys. Brain Res. 1975;98(1):119-34.

78 Namba S, Wani T, Shimizu Y, Fujiwara N, Namba Y, Nakamua S, et al. Sensory and motor responses to deep brain stimulation. Correlation with anatomical structures. J Neurosurg. 1985 Aug;63(2):224-34.

79 Sandberg DE, Segal M. Pharmacological analysis of analgesia and self-stimulation elicited by electrical stimulation of catecholamine nuclei in the rat brain. Brain Res. 1978;152(3): $529-42$.

80 Schmidek HH, Fohanno D, Ervin FR, Sweet WH. Pain threshold alterations by brain stimulation in the monkey. J Neurosurg. 1971; 35(6):715-22.

81 Segal M, Sandberg D. Analgesia produced by electrical stimulation of catecholamine nuclei in the rat brain. Brain Res. 1977;123(2):369_ 72.

82 Ostrowsky K, Magnin M, Ryvlin P, Isnard J, Guenot M, Mauguière F. Representation of pain and somatic sensation in the human insula: a study of responses to direct electrical cortical stimulation. Cereb Cortex. 2002 Apr; 12(4):376-85.

83 Denis DJ, Marouf R, Rainville P, Bouthillier A, Nguyen DK. Effects of insular stimulation on thermal nociception. Eur J Pain. 2016 May; 20(5):800-10.

84 Alonso-Matielo H, Gonçalves ES, Campos M, Oliveira VRS, Toniolo EF, Alves AS, et al. Electrical stimulation of the posterior insula induces mechanical analgesia in a rodent model of neuropathic pain by modulating GABAergic signaling and activity in the pain circuitry. Brain Res. 2021;1754:147237.

85 Prado WA, Raghubir R, Roberts MHT. Long duration antinociception induced by red nucleus stimulation in the rat. Pain. 1984;18: S329.

86 Ding CP, Guo YJ, Li HN, Wang JY, Zeng XY. Red nucleus interleukin- 6 participates in the maintenance of neuropathic pain through JAK/STAT3 and ERK signaling pathways. Exp Neurol. 2018 Feb;300:212-21.

87 Zarin DA, Tse T, Williams RJ, Rajakannan T. Update on trial registration 11 years after the ICMJE policy was established. N Engl J Med. 2017 Jan;376(4):383-91. 